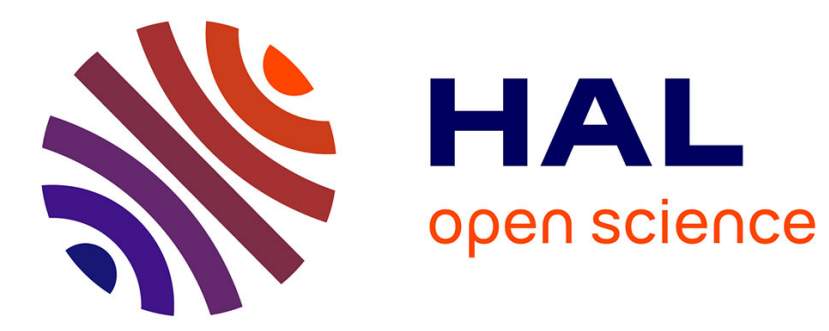

\title{
How topographic smoothing contributes to differences between the eddy flows simulated by sigma- and geopotential-coordinate models
}

Thierry Penduff, Bernard Barnier, Marie-Aurélie Kerbiriou, Jacques Verron

\section{- To cite this version:}

Thierry Penduff, Bernard Barnier, Marie-Aurélie Kerbiriou, Jacques Verron. How topographic smoothing contributes to differences between the eddy flows simulated by sigma- and geopotentialcoordinate models. Journal of Physical Oceanography, 2002, 32 (1), pp.122-127. 10.1175/15200485(2002)0322.0.CO;2 . hal-00182346

\section{HAL Id: hal-00182346 \\ https://hal.science/hal-00182346}

Submitted on 19 Mar 2020

HAL is a multi-disciplinary open access archive for the deposit and dissemination of scientific research documents, whether they are published or not. The documents may come from teaching and research institutions in France or abroad, or from public or private research centers.
L'archive ouverte pluridisciplinaire HAL, est destinée au dépôt et à la diffusion de documents scientifiques de niveau recherche, publiés ou non, émanant des établissements d'enseignement et de recherche français ou étrangers, des laboratoires publics ou privés. 


\title{
How Topographic Smoothing Contributes to Differences between the Eddy Flows Simulated by Sigma- and Geopotential-Coordinate Models
}

\author{
THIERRY PENDUFF \\ Center for Ocean-Atmospheric Prediction Studies, The Florida State University, Tallahassee, Florida \\ Bernard Barnier, Marie-Aurélie Kerbiriou, and JACQues Verron \\ Laboratoire des Écoulements Géophysiques et Industriels, Grenoble, France
}

\begin{abstract}
The characteristics of the mesoscale turbulence simulated at a resolution of $1 / 3^{\circ}$ by a sigma-coordinate model (SPEM) and a geopotential-coordinate model (OPA) of the South Atlantic differ significantly. These two types of models differ with respect to not only their numerical formulation, but also their topography (smoothed in SPEM, as in every sigma-coordinate application). In this paper, the authors examine how these topographic differences result in eddy flows that are different in the two models. When the topography of the Agulhas region is smoothed locally in OPA, as is done routinely in SPEM, the production mechanism of the Agulhas rings, their characteristics, and their subsequent drift in the subtropical gyre, are found to converge toward those in SPEM. Furthermore, the vertical distribution of eddy kinetic energy (EKE) everywhere in the basin interior becomes similar in SPEM and OPA and, according to some current meter data, becomes more realistic when mesoscale topographic roughness is removed from the OPA bathymetry (as in SPEM). As expected from previous process studies, this treatment also makes the sensitivity of the Agulhas rings to the Walvis Ridge become similar in SPEM and OPA. These findings demonstrate that many properties of the eddies produced by sigma- and geopotential-coordinate models are, to a significant extent, due to the use of different topographies, and are not intrinsic to the use of different vertical coordinates. Other dynamical differences, such as the separation of western boundary currents from the shelf or the interaction of the flow with the Zapiola Ridge, are attributed to intrinsic differences between both models. More generally, it is believed that, in the absence of a correct parameterization of current-topography interactions, a certain amount of topographic smoothing may have a beneficial impact on geopotential coordinate model solutions.
\end{abstract}

\section{Introduction}

Different ocean numerical models implemented at the same resolution in the same basin and forced in the same way produce significantly different results. This was clearly demonstrated by the DYNAMO Experiment (Willebrand et al. 2001; Barnier et al. 2001; New et al. 2001), which made a detailed comparison of the solutions from a sigma-coordinate model, a geopotential-coordinate model, and an isopycnic model of the North Atlantic at a resolution of $1 / 3^{\circ}$. Additional evidence comes from the work of Penduff et al. (2001), who compared the nearsurface mean currents and eddy kinetic energy (EKE) fields produced by a sigma-coordinate model and a geopotential-coordinate model of the South Atlantic at the same resolution. Both studies reveal that these two types

Corresponding author address: Thierry Penduff, Center for OceanAtmospheric Prediction Studies, The Florida State University, Johnson Building, 2035 E. Paul Dirac, Suite 200, Tallahassee, FL 323062840.

E-mail: tpenduff@coaps.fsu.edu. of models are able to simulate the broad features of the general circulation but that the details of their mean solutions can strongly differ, in particular in regions where the interactions between currents and topography are crucial. In the above studies, most differences appear along the Gulf Stream, the Brazil and Agulhas Currents (with regard to their separation from the coast), within alongshore flows such as the Malvinas Current (transport and northward overshoot), and along the branches of the Antarctic Circumpolar Current (ACC) and the North and South Atlantic Currents (path and deflection by bottom topography). Since the mean and eddy flows are closely interconnected and interact with topography, important differences are also found in the EKE fields simulated by the different models.

According to the authors cited above, some of these differences are due to the numerical formulation of the models, especially the representation of topography within each vertical coordinate system. Geopotentialcoordinate models rely on a piecewise constant approximation of the topography: isobaths appear as hor- 
izontal staircases, and slopes as vertical staircases. At every location and at any depth in these models, alongslope horizontal currents are subjected to a spurious sidewall friction, in particular where the topographic gradient is not oriented zonally or meridionally (Adcroft and Marshall 1998), and downslope currents are represented as a succession of advective and convective events. Sigma-coordinate models rely on a piecewise linear approximation of the topography: the deepest computational level follows a smoothed version of the sloping ocean floor. At distance from the land-sea mask their topography is made of sloping flat surfaces locally tangent to the smoothed topography, along which alongand downslope currents are only subjected to bottom friction. Since topographic effects propagate upward, the barotropic and surface circulations produced by both types of models can differ significantly in the vicinity of coastal shelves and above topographic structures (thus over most of the Atlantic).

Unlike in geopotential-coordinate models, the bathymetry is smoothed in sigma-coordinate models so as to reduce truncation errors in the computation of the pressure gradient terms (Barnier et al. 1998). This operation also removes the smallest scales from sigmacoordinate model topographies. At a resolution of $1 / 3^{\circ}$, this corresponds to a removal of mesoscale topographic roughness (hereafter MTR), a feature that was shown by Böning (1989) and Barnier and Le Provost (1989) to strongly affect the vertical distribution of kinetic energy and, presumably, the interactions between currents and topography. The smoothed bathymetries used in sigma-coordinate models are often considered as less realistic (less rough and steep) than their geopotentialcoordinate counterparts. However, Penduff et al. (2001) showed that, in many regions of the South Atlantic, the current-topography interactions simulated by a smoothbottomed sigma-coordinate model were more realistic than those simulated by a rough-bottomed geopotentialcoordinate model. One may thus wonder if geopotentialcoordinate models are able to take full advantage of their rougher, steeper, and thus apparently more realistic topography. In any case, differences in the solutions produced by sigma- and geopotential-coordinate models may not only be intrinsic to the choice of the vertical coordinate system, but may also be, in a simpler way, the consequence of the different topographic smoothing applied in their usual configurations. Previous studies comparing these types of models, such as those cited above, were not able to discriminate clearly between these two causes.

It is the purpose of this paper to examine the contribution of topographic smoothing in shaping the model solutions at a given resolution, corresponding to the "eddy permitting" regime. Of course, $13^{\circ}$ models are too coarse to represent accurately the oceanic mesoscale turbulence, but they are still (and will certainly remain) widely used for their ability to produce mesoscale features at reasonable computer cost. We shall investigate whether the differences in the topographies used in sigma- and geopotential-coordinate models can explain their different dynamical behaviors with respect to eddy flow and the distribution of eddy kinetic energy. To achieve this, some topographic sensitivity studies are performed with a geopotential-coordinate model of the South Atlantic, and the solutions compared to that of a sigma-coordinate model implemented on the same basin. More precisely, we investigate whether and how the EKE field produced by the geopotential-coordinate model changes (and eventually converges toward that produced by the sigma-coordinate model) according to the smoothing applied to its topography.

Section 2 presents the models and numerical configurations used in this study. The EKE fields produced by the sigma- and the geopotential-coordinate models with their "original" bathymetries are then compared in section 3. Various sensitivity experiments performed with the geopotential-coordinate model are then presented, focusing on the eddy flow: the bottom topography is smoothed globally (section 4) and locally (section 5), and is roughened again to highlight the impact of MTR (section 6). Insights are gained into which dynamical features differ in the two models because of topographic differences, the remaining dynamical differences then being attributed to the choice of the coordinate system. Our main findings are summarized in section 7 .

\section{Numerical configurations and topographies}

The geopotential-coordinate and the sigma-coordinate regional models used in this study will be referred to as LEVEL and SIGMA, respectively. The reader is referred to Penduff et al. (2001) for a complete description of the models and the initial configurations. Both models are implemented on the South Atlantic at a resolution of $\left(1 / 3^{\circ}\right) \cos \phi$ in latitude $\phi$ and driven by the same surface forcing. Four simulations were performed with LEVEL for the present study, the runs differing only with respect to their topographies away from the open boundaries. Three open boundaries radiate outgoing perturbations outside the domain and relax the model variables toward climatological states. The location $\left(68^{\circ} \mathrm{W}, 30^{\circ} \mathrm{E}\right.$, and $\left.16^{\circ} \mathrm{S}\right)$ and formulation of these open boundaries are the same in all the experiments (SIGMA and LEVEL) presented in the present study. The fields to which model variables are relaxed along the boundaries are the same in the various LEVEL configurations presented below. Time-averaged fields simulated by LEVEL along the open boundaries are also similar in LEVEL configurations: dynamical differences between LEVEL solutions (and with respect to the solution in SIGMA) are thus not due to differences in the lateral forcing. Since all LEVEL parameters were kept the same in the various experiments, LEVEL solutions essentially differ by virtue of their different topographies. 
It is worth noting here that only SIGMA includes the Weddel Sea, and that SIGMA and LEVEL respectively use 25 and 43 levels in the vertical. These vertical resolutions were chosen independantly because SIGMA and LEVEL were developed for different purposes. Previous tests performed during the Clipper experiment (Tréguier et al. 1999) showed only few differences in the LEVEL solution when using 72 levels instead of 43. The previous vertical resolution in SIGMA (20 levels) was increased to 25 to improve the representation of deep water masses. The ratio of the numbers of levels used in SIGMA and LEVEL is of the same order as that chosen during DYNAMO for the sigma and geopotential coordinate models. Additional comment about the vertical discretization in the two models are given in Penduff et al. (2001).

Topographic smoothing is routinely performed in sigma coordinate models to remove steep topographic slopes, which may generate spurious velocities through pressure gradient errors, and to remove small-scale topographic features that would induce fluctuations on sigma levels throughout the water column. The topographic smoothing performed in SIGMA is presented in detail in Béranger (2000). To summarize, the $1 / 12{ }^{\circ}$ ETOPO5 bathymetric dataset from the National Geophysical Data Center was interpolated onto the $1 / 3^{\circ}$ horizontal grid. Isolated points were removed by simple averaging of the neighboring depths; a circular Hanning filter was then applied with a relaxation toward the original topography in some key areas (sills, deep channels). Finally, a Shapiro filter was applied locally until the criterion proposed by Beckmann and Haidvogel (1993) to ensure hydrostatic consistency in sigma-coordinate models was satisfied. This treatment removed the smallest scales from the SIGMA topography but preserved important topographic features (Fig. 1a).

The four LEVEL topographies used in the present study derive from that used in the model of the Atlantic Ocean implemented in the Clipper experiment (Tréguier et al. 1999). For this experiment, the $1 / 12$ topographic dataset of Smith and Sandwell (1997) was interpolated onto the $1 / 3^{\circ}$ horizontal grid without any additional smoothing. The interpolation of local depths onto the 43 model vertical levels induces a certain distortion but, unlike in SIGMA, this overall treatment does not eliminate MTR nor reduce steep slopes. With respect to these two criteria, the Clipper topography is apparently more realistic than that used in SIGMA. Our first experiment (hereafter referred to as the "pivot" experiment) simply uses the southern part of this Clipper topography (Fig. 1b), which will thus be qualified as the "raw" topography.

The second LEVEL experiment uses a topography that was derived from the raw bathymetry following a global smoothing; this will be referred to as the "globally smoothed" bathymetry (abbreviated as GS). This global smoothing operator simply replaces each depth point by the average of the neighboring depth points within a centered $9 \times 9$ point box, and reinterpolates the result on the model vertical levels. This produces a smooth field (Fig. 1c), designed to determine whether LEVEL results tend toward SIGMA results after a topographic smoothing. However, the formulation and position of the open boundaries, the climatological forcing along them, the topography within 4-point-wide bands along them, and the land-sea mask are strictly the same in all LEVEL experiments.

We shall also present the results obtained in a third LEVEL experiment after local smoothing of the raw bathymetry. This so-called locally-smoothed bathymetry (LS) is the same as the raw topography everywhere, except in the areas A and B shown in Fig. 1d where it progressively becomes identical to GS (smoothed). This topography was designed to investigate the impact of topographic smoothing on the Agulhas rings production processes, and on the Subantarctic Front and Malvinas Current.

Finally, the specific impact of MTR is evaluated in a fourth experiment in which some random mesoscale topographic structures, synthetized from a predefined spectrum, are added onto the GS bathymetry at distance from the shelves. This artificially roughed topography, referred to as GSR (for "globally smoothed + roughness") hereafter, is shown in Fig. 1e. The artificial MTR is isotropic, defined by a wavenumber spectrum similar to that used by Böning (1989) with an Rms height of $400 \mathrm{~m}$. Since the wavenumbers of the synthetized MTR are defined in terms of grid points, their horizontal scales progressively decrease southward in proportion to the grid size. This synthetized MTR is added to the GS topography and the result is interpolated on the model vertical levels. The wavenumber spectrum of the GSR topography is shown by the black triangles in Fig. 1f, along with those of the raw, GS, and SIGMA topographies. The smoothing method employed to build GS from the raw topography eliminated most of the topographic scales smaller than about $1000 \mathrm{~km}\left(\right.$ at $30^{\circ} \mathrm{S}$ ), and these are more or less reintroduced in GSR as artificial MTR. The GSR simulation, whose topography appears rougher than the raw topography at mesoscale

\footnotetext{
FIG. 1. Bottom topography (in meters) used in the five numerical simulations (a) to (e) (see Table 1 for characteristics). The color scale is the same in these five panels. The subdomains over which the vertical profiles of EKE have been averaged in Fig. 4 are shown in (a) (clockwise from upper left: western subtropical gyre, eastern subtropical gyre, eastern ACC, western ACC). The dashed-dotted black line in (a) at $32.9^{\circ} \mathrm{S}$ locates the section along which topographies are shown in Fig. 2. (f) Power spectrum estimates of the SIGMA, pivot, GS, and GSR topographies (in $\mathrm{m}^{2}$ ). Wavenumbers (lower horizontal axis) are expressed in number of cycles in the zonal direction; corresponding wavelengths at $30^{\circ}$ and $50^{\circ} \mathrm{S}$ [average latitudes of the subdomains drawn in (a)] are indicated in kilometers along the vertical dotted lines.
} 

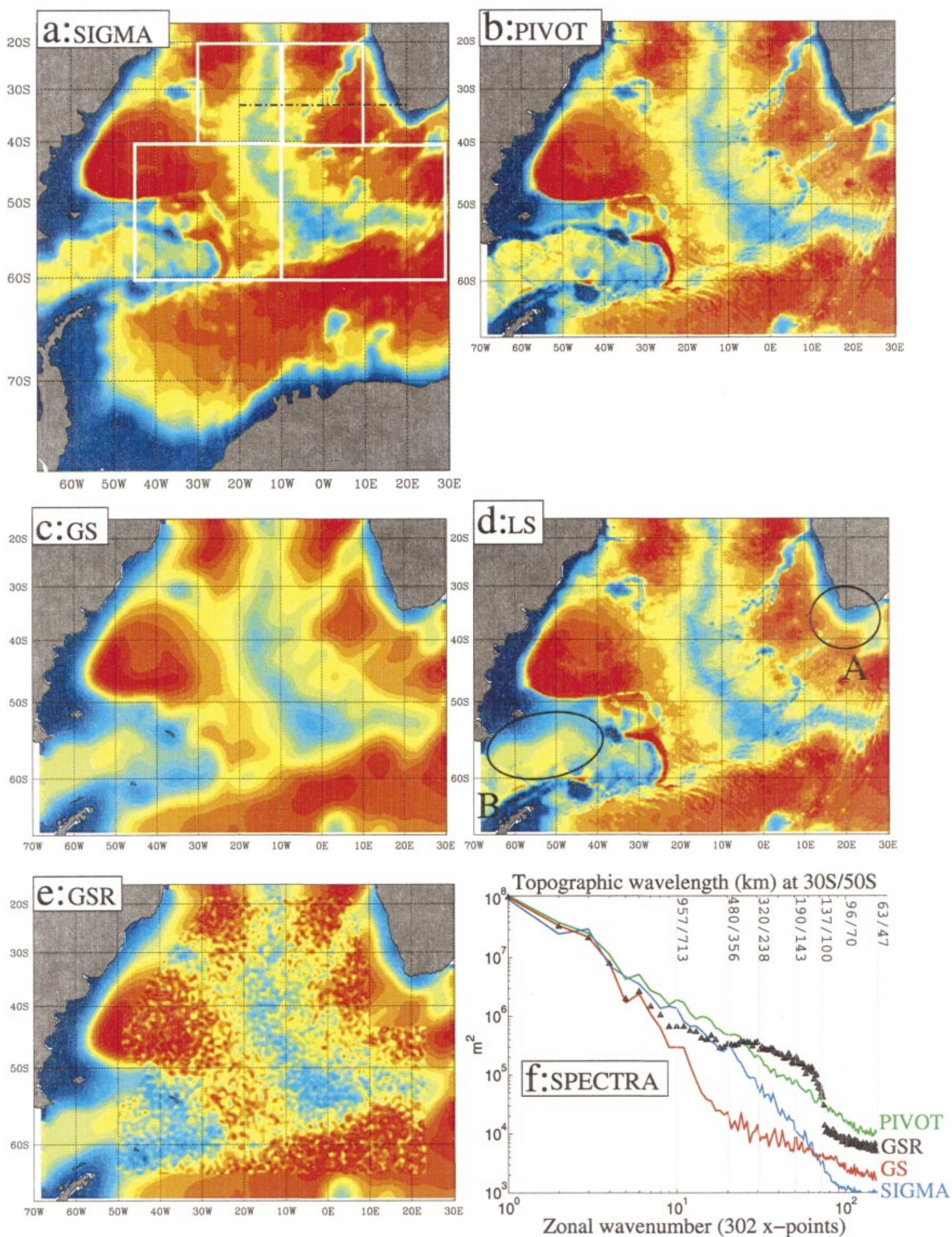

Depth in meters

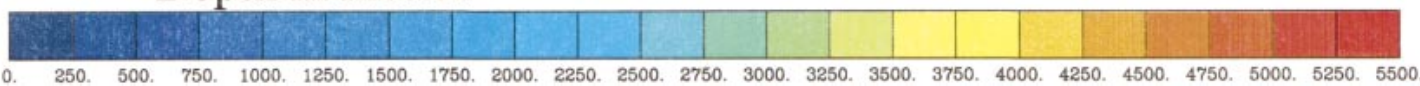



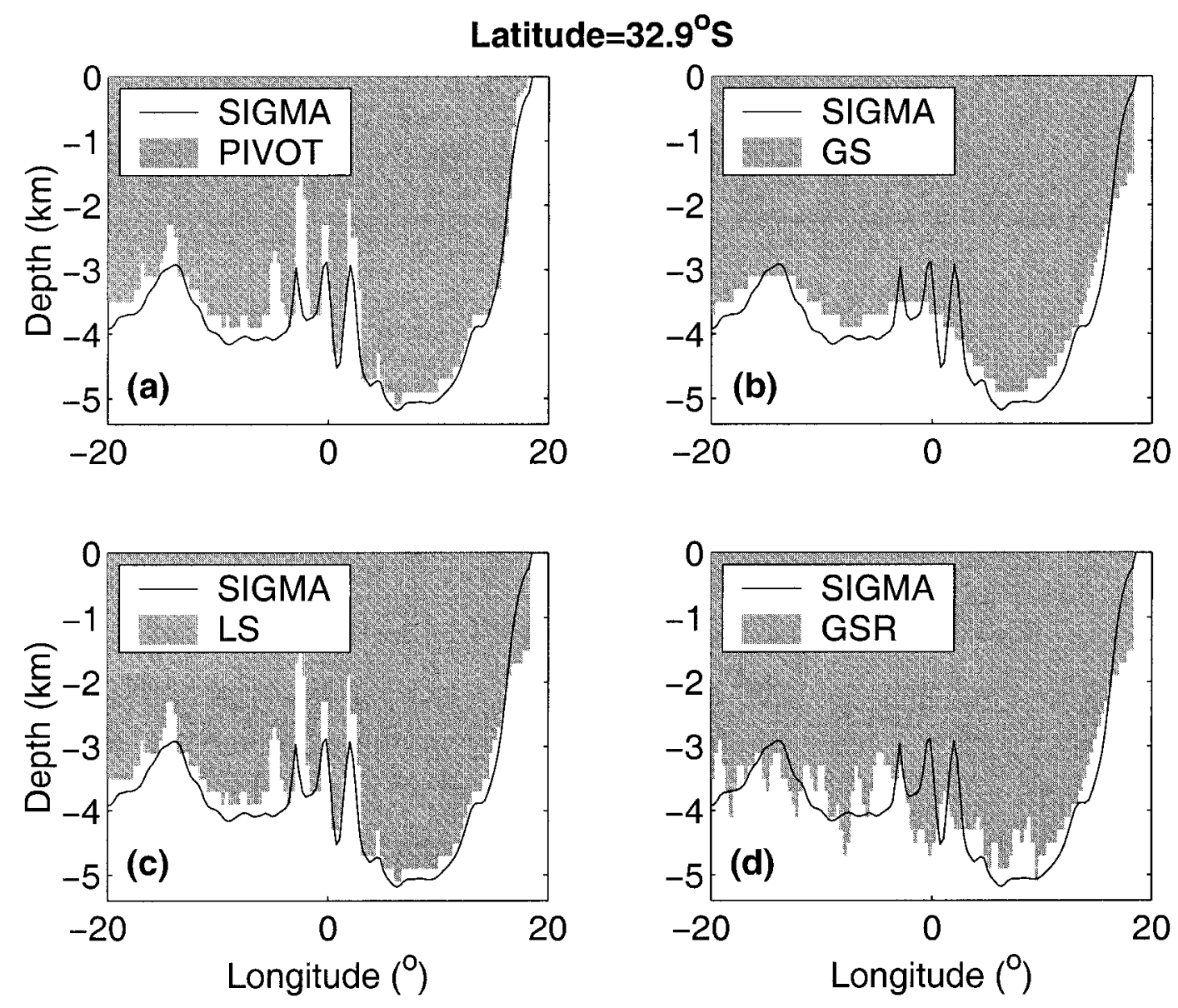

FIG. 2. SIGMA and LEVEL topographies along $32.9^{\circ} \mathrm{S}$ between $20^{\circ} \mathrm{W}$ and $20^{\circ} \mathrm{E}$ (section shown in Fig. 1): (a) Pivot, (b) GS, (c) LS, and (d) GSR. This section intersects the Mid-Atlantic Ridge, the Walvis Ridge, and the South African shelf from west to east.

(wavelengths between 140 and $400 \mathrm{~km}$ ), will be compared to the GS simulation to evaluate the impact of MTR. Figure 1f (blue and green curves) also shows that the topographic spectrum of SIGMA is similar to that of the LEVEL raw topography at scales larger than about $500 \mathrm{~km}$ at $30^{\circ} \mathrm{N}$, but contains less mesoscale roughness (smaller wavelengths).

Figure 2 shows in detail the different model topographies along $32.9^{\circ} \mathrm{S}$ across the Cape Basin. This figure highlights the presence of staircases in LEVEL bathymetries, gives an image of the smoothing performed in the SIGMA topography, of the transition between the smooth and unsmoothed regions in the LS topography, and of the features and eastward extension of the artificial MTR in the GSR bathymetry. The GS topography appears much smoother (less rough and steep) than that in SIGMA in the upper-right panel of Fig. 2. We will come back to this important feature in section $4 \mathrm{c}$.

The intrinsic differences between both models could be identified by comparing their solutions over the same topography (that of SIGMA). We did not perform a LEVEL integration with SIGMA topography for the fol- lowing reasons. First, this would have required the complete redefinition of the LEVEL configuration and associated surface forcing fields because both models use different grids and land-sea masks. Second, the interpolation onto LEVEL vertical levels would have distorted the SIGMA topography and perturbed the comparison. Finally, it is likely that the dynamical differences between SIGMA and LEVEL with SIGMA topography would have been similar to those observed between SIGMA and the LEVEL pivot experiment, because SIGMA and pivot topographies are not very different in terms of smoothing (Fig. 2). It will be shown in the following that several intrinsic differences between both models may, though, be identified without running LEVEL with SIGMA topography. This issue is discussed again in the conclusion.

The distinctive features of the five numerical simulations presented above are summarized in Table 1. SIGMA was integrated over $24 \mathrm{y}$ and the final EKE fields computed over the last $6 \mathrm{y}$. LEVEL was integrated over $15 \mathrm{y}$ with the raw topography, but, in this simulation, the mean EKE field computed over the years 10-15 
TABLE 1. Numerical experiments and associated topographies.

\begin{tabular}{|c|c|c|c|}
\hline Expt & Model & Topography & $\begin{array}{l}\text { Color in } \\
\text { Figs. 1f and } 4\end{array}$ \\
\hline SIGMA & SPEM & $\begin{array}{l}\text { Smoothed to reduce trunca- } \\
\text { tion errors }\end{array}$ & Blue \\
\hline PIVOT & OPA & $\begin{array}{l}\text { Same as in the CLIPPER ex- } \\
\text { periment }\end{array}$ & Green \\
\hline GS & OPA & $\begin{array}{l}\text { Globally smoothed from } \\
\text { PIVOT }\end{array}$ & Red \\
\hline LS & OPA & $\begin{array}{c}\text { Same as PIVOT, smoothed in } \\
\text { areas } \mathrm{A} \text { and B of Fig. 1a }\end{array}$ & Black \\
\hline GSR & OPA & $\begin{array}{l}\text { Same as GS with artificial } \\
\text { mesoscale roughness in } \\
\text { deep areas }\end{array}$ & Black triangles \\
\hline
\end{tabular}

does not differ significantly from that computed between the years 3.5-6.5. The same remark also holds for the GS and GSR simulations, which were both integrated over $13 \mathrm{y}$. We will thus compare the EKE fields computed over the years 3.5-6.5 in the four LEVEL simulations.

\section{Eddy flow in the LEVEL pivot experiment and in SIGMA}

In both models, mesoscale turbulence is essentially produced by baroclinic instability in the main thermocline, located around $350 \mathrm{~m}$ in every simulation. During this process, some available mean potential energy (MPE) is transferred to the EKE baroclinic modes. The mean circulation and the EKE produced at this depth (350 $\mathrm{m}$ ) in SIGMA and in the LEVEL pivot experiment (raw topography) have been compared by Penduff et al. (2001); Figures 3a and 3b present the EKE fields at the surface $(6 \mathrm{~m})$. Since the eddy flow is well correlated on the vertical, the horizontal distribution of EKE is qualitatively the same at depth (not shown) as near the surface: the vertical structure of the EKE field can thus be analyzed through vertical profiles. The vertical EKE distribution is the result of complex mechanisms that involve the strength of baroclinic instability (the transfer rate from MPE to EKE), the density stratification that controls the vertical distribution of geostrophic velocities (through the hydrostatic pressure field), and the MTR (which affects the intermodal exchanges, the inverse cascade of energy, and consequently the EKE vertical profile). The blue and green curves in Fig. 4a represent the vertical profiles of EKE in SIGMA and in the LEVEL pivot experiment, horizontally averaged within the four subdomains shown in Fig. 1a. To quantify the downward penetration of EKE from the thermocline, the EKE profiles presented in Fig. 4a have been normalized by their value at $350 \mathrm{~m}$ (Fig. 4b): this penetration will be simply quantified as the percentage of thermocline EKE that reaches $3000 \mathrm{~m}$. Figure 5 presents snapshots of the eddy flow in the Agulhas region for the different simulations, and Fig. 6 presents vertical profiles of EKE estimated from WOCE current meter clusters located within our two subtropical subdomains (see Table 2).

\section{a. Surface eddy flow}

Penduff et al. (2001) showed that SIGMA is able to reproduce the separation of the Brazil Current from the coast in the Confluence region and the observed $\mathrm{C}$-shape structure of the surface EKE field wrapped around a minimum above the Zapiola Ridge (cf. Figs. 3a and 3f). In contrast, the Brazil Current produced by LEVEL remains attached to the American shelf, no EKE minimum is found above the Zapiola Ridge, and the EKE maxima associated with the Subtropical and Subantarctic Fronts are closer to each other (Fig. 3b). In the LEVEL pivot experiment, the Agulhas Current remains close to the shelf and very regularly produces rings through the occlusion of the retroflection loop (Fig. 5b). All these rings are anticyclonic, rather small with diameter of about $180-250 \mathrm{~km}$ instead of about $300 \mathrm{~km}$ in the real ocean (Peterson and Stramma 1991), take the same northwestward path into the South Atlantic as shown by the straight-line EKE extension in Fig. 3b, and persist beyond the Walvis Ridge. In SIGMA, the Agulhas Current is less attached to the shelf and produces both anticyclonic and cyclonic eddies [confirmed by float trajectories, Boebel et al. (2000)] of various sizes through the instability of its strong pulsating retroflecting cell, centered around $20^{\circ} \mathrm{E}$ (Fig. 5a). The deformations of this cell suggest that, unlike in the LEVEL pivot experiment, baroclinic instability is involved in ring production. This hypothesis is supported by the experiments presented in sections $4 \mathrm{a}$ and $5 \mathrm{c}$. The rings that drift into the Atlantic in SIGMA are larger and realistically spread out meridionally (Fig. 3a) but, unrealistically, do not persist beyond the Walvis Ridge. Above the southern part of the Mid-Atlantic Ridge, the America-Antarctic and Southwest Indian Ridges $\left(60^{\circ}-50^{\circ} \mathrm{S}, 25^{\circ} \mathrm{W}-0^{\circ}\right)$, the surface EKE level ranges between 100 and $250 \mathrm{~cm}^{2} \mathrm{~s}^{-2}$ in the LEVEL pivot experiment, that is, about twice that produced by SIGMA and that deduced from altimetric measurements (see Figs. 3b, 3a, and 3f). This local maximum is correlated with bathymetry, showing once again the strong dynamical impact of different currenttopography interactions in the two models.

\section{b. Vertical distribution of EKE}

Compared to the LEVEL pivot experiment, eddy motions are more energetic in SIGMA at all depths (green and blue curves in Fig. 4a): EKE levels in SIGMA are 1.5 to 2.5 times greater near the surface (except in the southwestern subdomain), and are 2 to 10 times greater below $1000 \mathrm{~m}$. Since the resolutions of the two models are similar, these differences are likely to come from a stronger EKE production rate (transfer from MPE to EKE) in SIGMA, and/or from a stronger EKE dissipation in the LEVEL pivot experiment. It is unexpected 

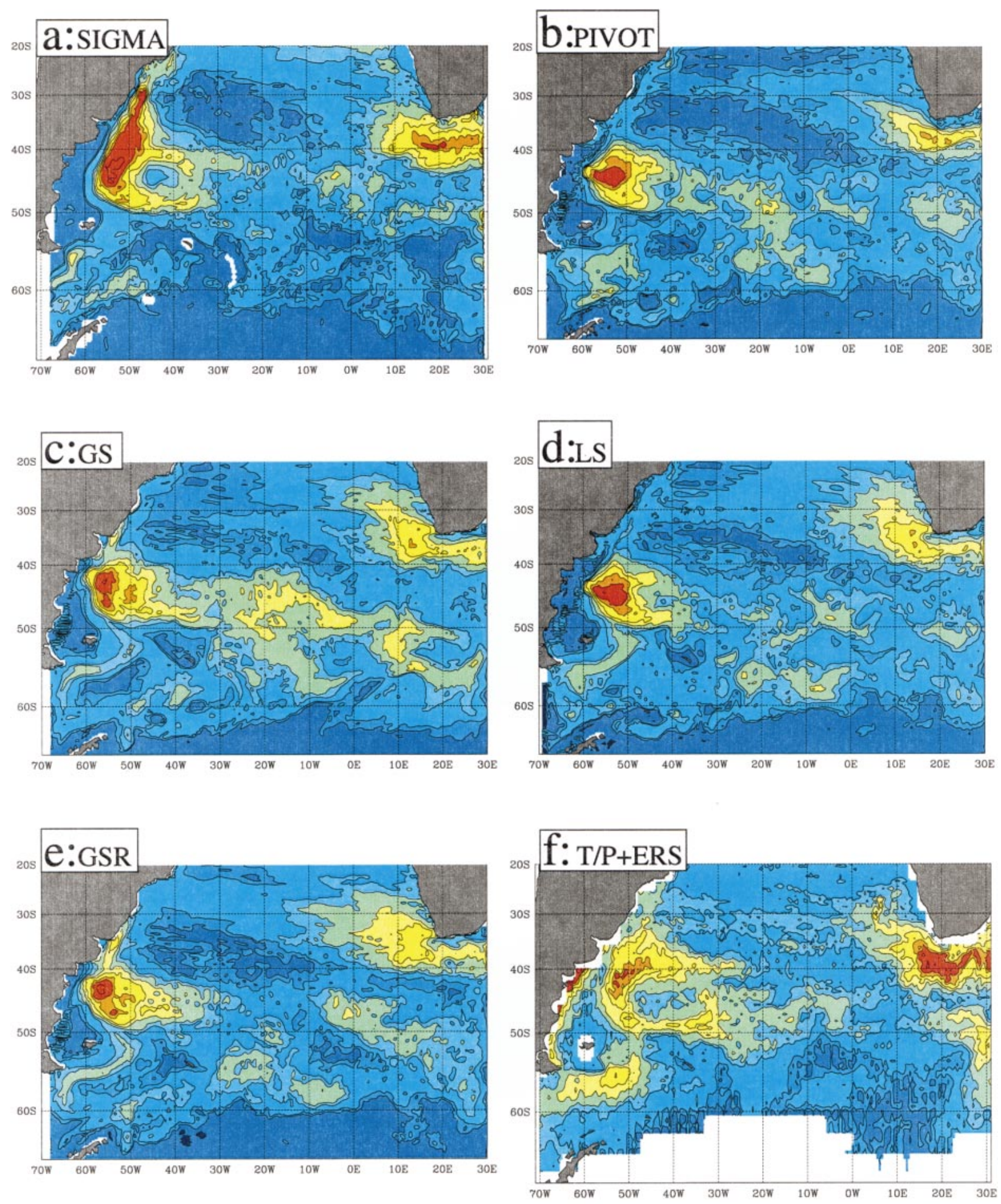

Surface EKE (cm2 s-2)

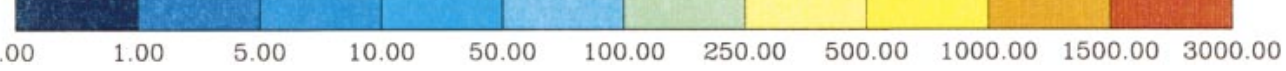


that the EKE production rate would be globally stronger in SIGMA, since the vertical and horizontal density gradients are rather similar in the two models. In SIGMA, however, the mean flow in the main regions of EKE production, that is, the Confluence and Agulhas regions, appears more realistic and the eddy production more efficient (Penduff et al. 2001). The turbulent activity may then be enhanced at distance from the production region through mean and self-advection, in particular within the subtropical gyre along the path of the Agulhas rings. As demonstrated by Böning (1989) and verified in section 6, the use of a rough topography in LEVEL contributes to this low level of EKE at depth.

\section{c. Downward penetration of thermocline EKE}

The green and blue curves in Fig. $4 \mathrm{~b}$ highlight the more baroclinic character of the EKE in the LEVEL pivot experiment compared to SIGMA: in most subdomains, only $12 \%$ of the EKE found at the depth of the thermocline in the pivot experiment penetrates as deep as $3000 \mathrm{~m}$ (as opposed to more than $20 \%$ in SIGMA). According to previous studies (Böning 1989; Barnier and Le Provost 1989, 1993), this EKE confinement near the surface may be caused by the presence of MTR in the pivot experiment. This feature may, in turn, reduce the sensitivity of Agulhas rings to bottom topography and affect their trajectories. Indeed, Beismann et al. (1999), using an idealized quasigeostrophic model, showed that relatively baroclinic Agulhas rings are less deviated and dispersed by ridgelike topographic structures than more barotropic rings. This effect seems to be confirmed by our simulations since only the relatively baroclinic Agulhas rings found in the roughbottomed LEVEL pivot experiment are able to drift beyond the Walvis Ridge.

Current meter measurements are only available at a few locations in the South Atlantic. We show in Figs. $6 \mathrm{a}$ and $6 \mathrm{~b}$ the EKE computed in the two clusters shown in Fig. 6c; the EKE has been computed for each current meter, and estimated at 350 and $3000 \mathrm{~m}$ for each cluster. Globally, it turns out that about $30 \%$ of the EKE measured at $350 \mathrm{~m}$ reaches $3000 \mathrm{~m}$. Comparing these EKE estimates with our subdomain-averaged EKE vertical profiles (Fig. 4) must be done with caution since these in situ measurements are local. However, it seems that the relatively strong downward penetration of EKE in SIGMA is more consistent with data than that in the LEVEL pivot experiment. This is likely to be due to the discretization of topography in LEVEL, which enhances bottom topography roughness.

\section{d. Subsequent strategy}

Dynamical differences between different models are usually attributed to different numerical formulations. We shall not focus on these intrinsic differences (whose dynamical impact is evident, but difficult to identify directly) but on the dynamical impact of the different topographies used in the two models. This feature is expected to affect the dynamics in two ways: (i) the bathymetries of the two models and subsequent representations of current-topography interactions in the main areas of EKE production (Confluence and Agulhas) are expected to affect the instability processes, the characteristics of eddies, and therefore the EKE distribution; (ii) according to previous studies, the removal of MTR in SIGMA is likely to affect the vertical distribution of EKE throughout the basin and, in the subtropical gyre, the trajectory and the lifetime of eddies. The impact of these topographic differences on the EKE field, and more particularly on the characteristics and fate of the Agulhas rings, is investigated in the next sections.

\section{Impact of global topographic smoothing on the eddy flow in LEVEL}

We examine here the way bottom topography contributes to some of the differences mentioned above by testing whether the mesoscale turbulence characteristics produced by LEVEL with a smoothed topography (GS, Fig. 1c) tend toward those simulated by SIGMA. Figure $3 c$ and the red curves in Figs. 4a and 4b, respectively, represent the surface EKE distribution, the subdomainaveraged vertical distribution of the EKE, and the downward penetration of thermocline EKE in the GS LEVEL experiment. The GS solution is compared with the LEVEL pivot and SIGMA solutions.

\section{a. Surface eddy flow in the Agulhas region}

Smoothing the topography in LEVEL leads to a complete change in the Agulhas rings production process, which becomes closer to that observed in SIGMA (Figs. 5a and 5c): the Agulhas Current is more baroclinic, flows above the smoothed Agulhas Bank, and feeds an anticyclonic, permanent, zonally elongated retroflection cell. In GS as in SIGMA, this cell fluctuates in shape and produces rings of both signs (cyclonic and anticyclonic), which are larger, stronger, and more realistic than in the pivot experiment. In the LEVEL pivot experiment, the characteristic length scale of the eddies appears to be smaller than that deducted from the bar-

FIG. 3. Mean surface EKE $\left(\mathrm{cm}^{2} \mathrm{~s}^{-2}\right)$ computed from the five simulations, and from the combination of TOPEX/Poseidon and ERS-1/2 altimetric data (Ducet et al. 2000). The color scale is the same in the six panels. 
(a)

\section{Vertical distribution of the EKE $\left(\mathrm{cm}^{2} \mathrm{~s}^{-2}\right)$}
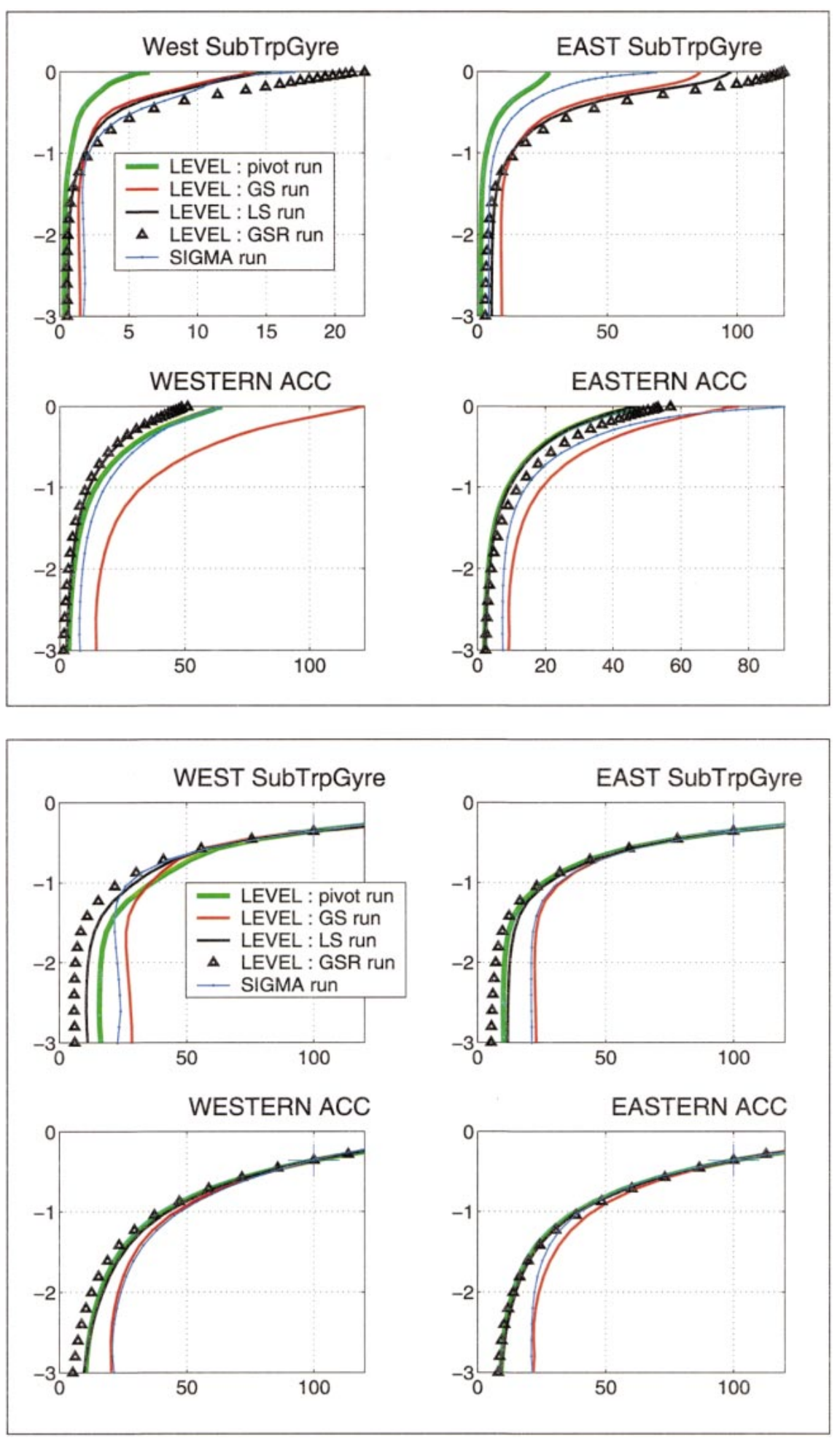

FIG. 4. (a) Vertical distribution of the EKE $\left(\mathrm{cm}^{2} \mathrm{~s}^{-2}\right)$ in the five simulations, horizontally averaged over the four subdomains displayed in Fig. 1a. (b) Same as in (a) but the profiles are scaled by the EKE at the depth of the thermocline $(350 \mathrm{~m})$, and multiplied by 100; the result is therefore expressed as a percentage of EKE relative to the 350-m level. 

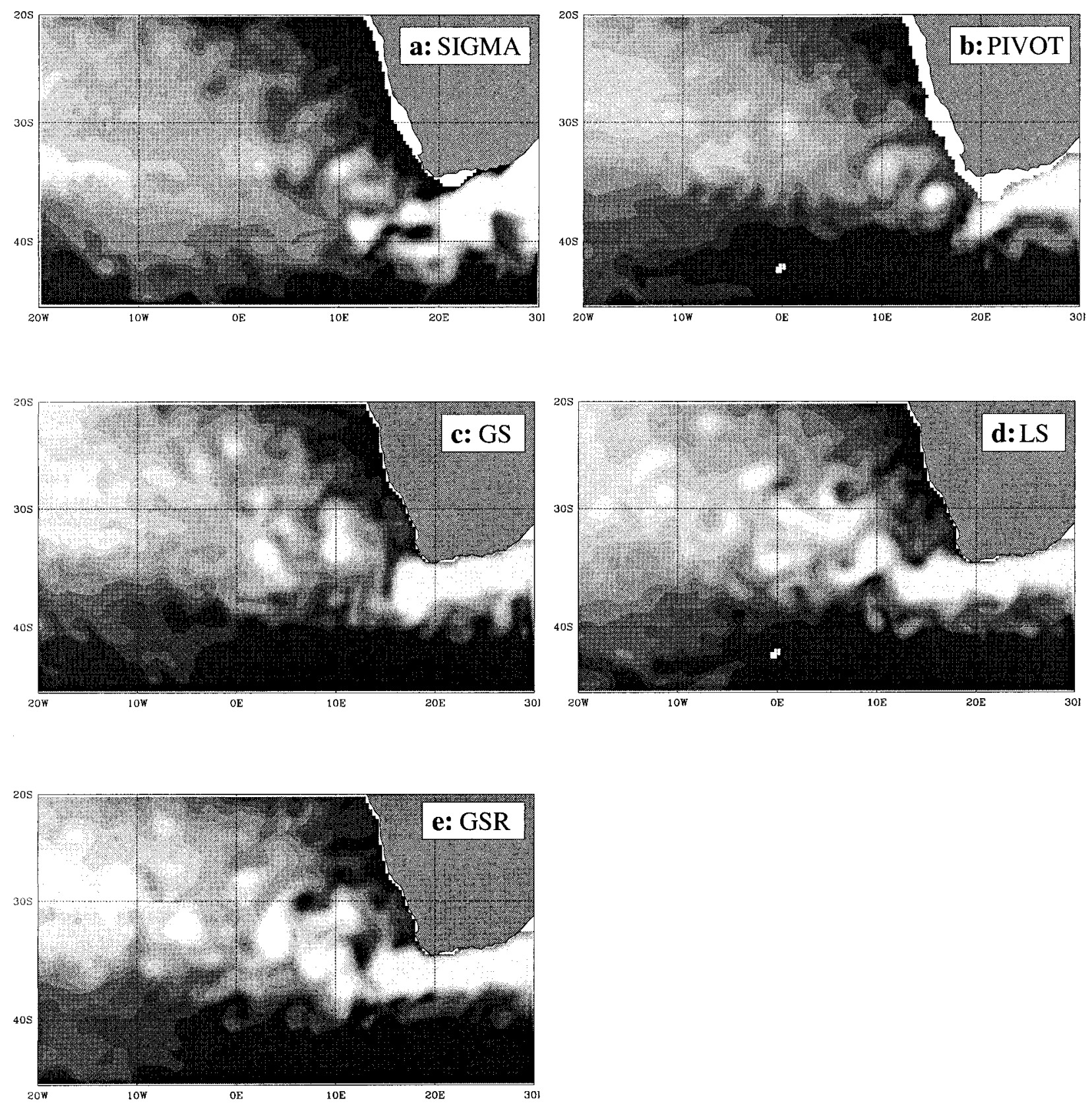

Temperature at $300 \mathrm{~m}$

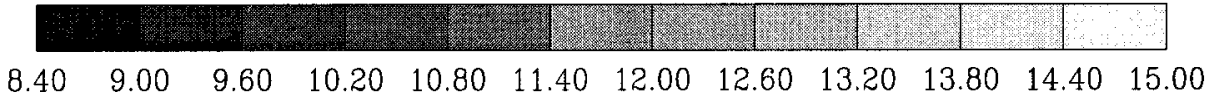

FIG. 5. Illustration of the dynamical regime in the Agulhas region: snapshots of the temperature field (in ${ }^{\circ} \mathrm{C}$ ) at $350 \mathrm{~m}$ in the five experiments, taken at a similar day of the year (second of July) in the SIGMA (panel a) and the four LEVEL experiments (panels b-e).

oclinic instability theory in the region of Agulhas rings production. In the GS experiment, those two length scales are similar. This strongly suggests that in the present context, topographies that are smoothed in the Agulhas region (SIGMA, GS, GSR, and LS as shown below) promote the contribution of baroclinic instability in the ring generation process. In comparison with the LEVEL pivot experiment, the surface EKE level in GS is not increased significantly in the production area, but the EKE plume that penetrates into the South Atlantic 
(a) Rio Grande

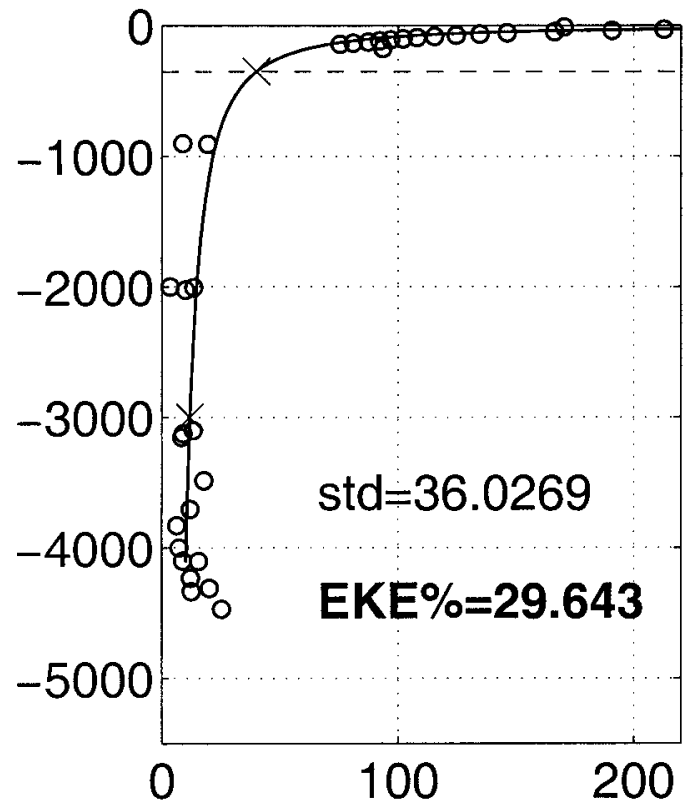

(b) Cape Basin

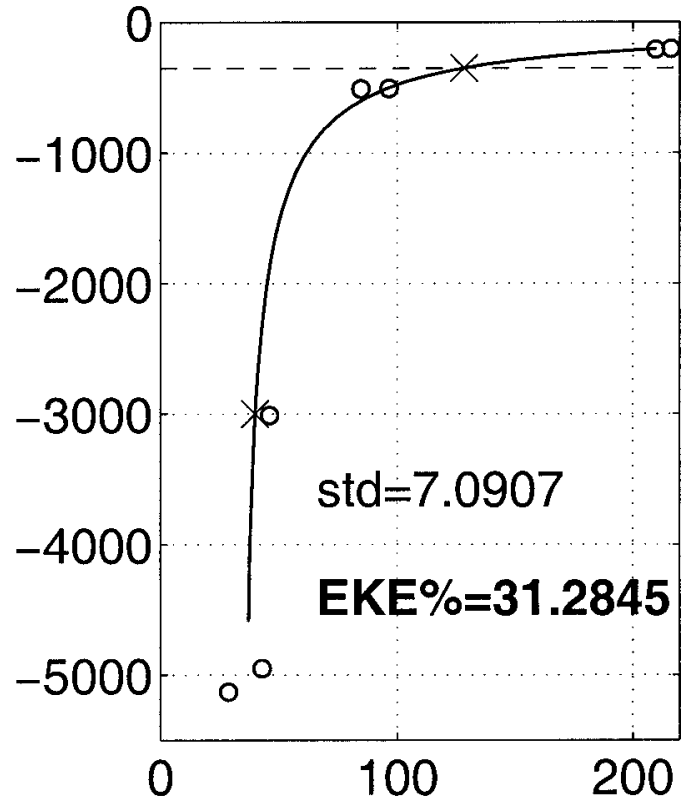

(c) Cluster Locations

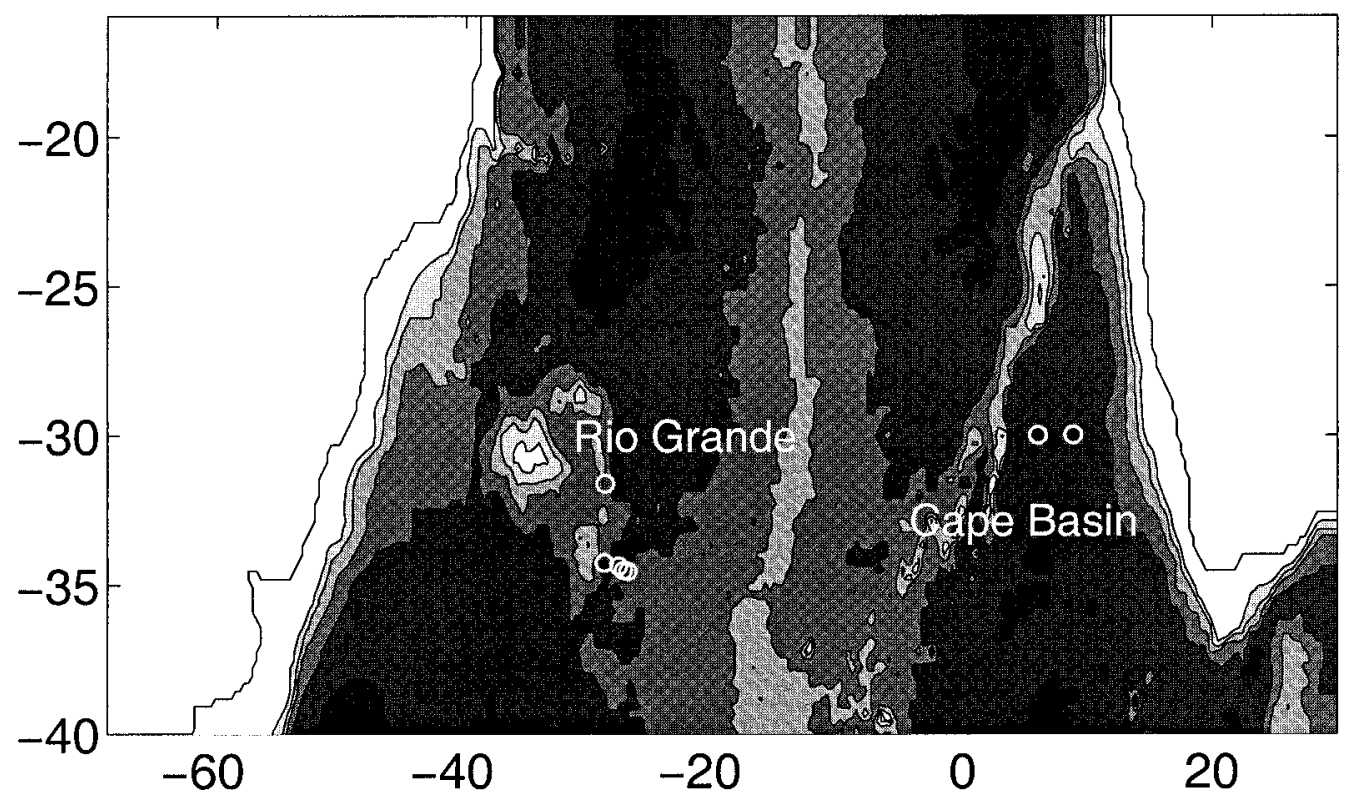

FIG. 6. Vertical distribution of the EKE $\left(\mathrm{cm}^{2} \mathrm{~s}^{-2}\right)$ from the WOCE current meter data. (c) Bottom topography (one contour every $1000 \mathrm{~m}$ ) and location of selected moorings, organized here in two clusters (see Table 2): five moorings east of the Rio Grande Rise, two in the Cape Basin. Those clusters are located in the western and eastern subtropical subdomains of Fig. 1a. (a) and (b) Circles show local EKE values computed within each cluster from low-passed (cutoff at 5 days) horizontal velocity time series to make them comparable with model estimates. At each cluster, immersion $z=350 \mathrm{~m}$ is indicated by a dashed line, $\mathrm{EKE}_{350 \mathrm{~m}}$ and $\mathrm{EKE}_{3000 \mathrm{~m}}$ are marked by large "X", EKE\% means $100 \% \times$ $\mathrm{EKE}_{3000 \mathrm{~m}} / \mathrm{EKE}_{350 \mathrm{~m}}$. The $\mathrm{X}$ marks are deduced from the second-order polynomial that fits best with the logarithm of data (plain line); std is the standard deviation of the data from the plain line. 
TABLE 2. Definition of the two WOCE current meter clusters: columns 2-5 define the longitude and latitude bands that locate each cluster and 6-7 give the dates of the first and last measurement for each cluster, column 8 gives the minimum duration of the times series taken into account to compute in situ EKEs (see Fig. 6).

\begin{tabular}{lcccccc}
\hline \hline Cluster & Min lon & Max lon & Min lat & Max lat & Min $t_{0}$ & $\begin{array}{c}\text { Minimum } \\
\text { duration }\end{array}$ \\
\hline Rio Grande & $29^{\circ} \mathrm{W}$ & $27^{\circ} \mathrm{W}$ & $35^{\circ} \mathrm{S}$ & $31^{\circ} \mathrm{S}$ & 13 Dec 1994 & $30 \mathrm{May} 1994$ \\
Cape Basin & $6^{\circ} \mathrm{E}$ & $9^{\circ} \mathrm{E}$ & $30^{\circ} \mathrm{S}$ & $30^{\circ} \mathrm{S}$ & 23 Jun 1992 & 29 Oct 1993 \\
\hline
\end{tabular}

is broader (Figs. 3b and 3c), in response to a change in the trajectories of the Agulhas rings (similar to those observed in SIGMA).

\section{b. Surface eddy flow in other regions}

Compared with the surface EKE level in the pivot experiment, that observed in the GS experiment globally doubles in the basin interior and becomes more comparable to satellite estimates in quiet regions, but only a slight increase in the EKE level is found within the Brazil and Malvinas Currents (Figs. 3a, 3b, 3c). Within the Scotia Sea (south of $50^{\circ} \mathrm{S}$ and west of $40^{\circ} \mathrm{W}$ ), the global topographic smoothing induces a clearer separation of the EKE maxima associated with the Subantarctic and Polar Fronts (Figs. 3b and 3c). In this area, the horizontal distribution of EKE in the GS experiment becomes similar to that in the SIGMA experiment (Fig. 3a). Unlike in the Agulhas region, the discrepancies observed in the Confluence region in the pivot experiment (no EKE minimum above the Zapiola Ridge, Subtropical Front too wide and located too far south) are unchanged despite the significantly different topography. This suggests that the inability of LEVEL to represent these processes is not linked with the definition of its topography, but with intrinsic limitations such as its staircaselike topography. This was the hypothesis proposed by de Miranda et al. (1999) and Penduff et al. (2001); our experiments support it.

\section{c. Vertical distribution of EKE}

Figure $4 \mathrm{a}$ (red and green curves) shows that the global topographic smoothing also induces a strong enhancement of the EKE in the deep ocean, becoming greater than that of SIGMA (blue curve) in most subdomains (note that topography is smoother in GS than in SIGMA). More interesting is the fact that the downward penetration of EKE in the GS experiment becomes very similar to that in SIGMA (Fig. 4b, red and blue curves) and, as suggested by Fig. 6, more consistent with data: more than $20 \%$ of the thermocline EKE penetrates as deep as $3000 \mathrm{~m}$ over most subdomains in the GS experiment. The increase and barotropization of the EKE in GS are probably linked with the removal of MTR (see section 6). We mentioned in section 2 that topography is apparently much smoother in GS than in SIGMA (Fig. 2b), but it turns out that the EKE downward penetration in those two simulations is quite similar.
This interesting feature strongly suggests that LEVEL staircaselike topography is dynamically rougher: the piecewise constant approximation of bathymetry (LEVEL) is likely to intrinsically produce more topographic roughness than the piecewise linear approximation (SIGMA), and to confine the EKE closer to the surface. Figures $4 \mathrm{~b}$ and 6 suggest that the downward penetration of EKE is more realistic in SIGMA (and GS) than in LEVEL with the original topography. It is very likely that this intrinsic roughness differentiates all geopotential- and sigma-coordinate models, whatever their resolution and their configuration.

\section{Impact of localized topographic smoothing on the eddy flow in LEVEL}

We evaluate here the extent to which the smoothing of the Agulhas region (from where a lot of mesoscale turbulence is exported westward) performed on the SIGMA topography contributes to the differences mentioned between this experiment and the LEVEL pivot experiment. This is done by comparing the eddy flow obtained in the LS simulation (Fig. 3d, black curves in Figs. 4a and 4b) with that obtained in the previous experiments. Since the LS topography also differs from the "raw" topography in the Scotia Sea (Figs. 1b and 1d), the effects of the topographic smoothing in region $\mathrm{B}$ are summarized first. The response of LEVEL in the rest of the basin is described afterward.

\section{a. West of $50^{\circ} \mathrm{W}$}

In the topographically smoothed area B of the LS experiment, the EKE maximum associated with the Subantarctic Front and the Malvinas Current extends continuously around the Falkland Plateau toward the Confluence region and is clearly separated from that associated with the Polar Front (Fig. 3d): the EKE field in area B is qualitatively close to its counterpart in the GS and SIGMA simulations. Therefore, as suggested by Penduff et al. (2001), the circulation simulated by LEVEL with the raw topography and by SIGMA in the Scotia Sea mainly differ because of the topographic smoothing performed there in the latter model. However, the EKE fields in the LS and pivot experiments do not differ significantly downstream of region B, either in the Confluence region or east of the smoothing area. This shows that the topographic smoothing performed in area B has no influence other than local. The other differences men- 
tioned hereafter between the LEVEL pivot and LS experiments are thus due to the topographic smoothing performed in area A.

\section{b. Within the $A C C$}

South of $40^{\circ} \mathrm{S}$ and east of $45^{\circ} \mathrm{W}$, the EKE fields computed from the pivot and LS experiments do not differ significantly. In other words, the horizontal distribution of EKE (cf. Figs. 3b and 3d), the EKE levels throughout the water column, and the downward penetration of the EKE from the thermocline within the ACC (green and black curves in Figs. 4a and 4b, lower panels) appear virtually insensitive to the topographic smoothings performed in areas A and B. The differences mentioned in section $4 \mathrm{c}$ between the GS and pivot experiments concerning the EKE distribution within the ACC are therefore independent of the treatment of topography in the remote areas A and B. It seems likely that local MTR is a better candidate for explaining the different downward penetration of EKE within the ACC in these latter two simulations and, consequently, in the SIGMA and LEVEL pivot experiments. This hypothesis is tested in section 6 .

\section{c. In the Agulhas region and the subtropical gyre}

Computer animations show that in the LS experiment, the instabilities of the Agulhas Current and the shape, size, diversity, and trajectories of the Agulhas rings are very similar to those found in the GS experiment (section 4a). Comparing the LS solution with the pivot solution clearly shows that the topographic smoothing in region $\mathrm{A}$ increases the strength and meridional spreading of the Agulhas rings (Figs. 5b and 5d), and, consequently, both the westward extension of the EKE maximum from the Agulhas region (Figs. 3b and 3d) and the order of magnitude of the EKE throughout the water column (green and black curves in Fig. 4a). All these features become similar to those found in the GS solution (red curves) throughout most of the subtropical gyre, confirming the large-scale impact of the Agulhas rings throughout the South Atlantic and the importance of area $\mathrm{A}$ in defining a model topography.

Furthermore, the LEVEL GS solution and the SIGMA solution were shown in section $4 \mathrm{a}$ to be similar with regard to these latter features (ring generation process, initial characteristics, trajectories, and ability to spread meridionally in the subtropical gyre). In other words, a topographic smoothing performed only in area A is sufficient to make the eddy flow produced by a geopotential-coordinate model similar to that of a sigma-coordinate model (and thus, more realistic) with respect to the Agulhas rings production process and initial characteristics, and, in turn, to some major features of the eddy field throughout the subtropical gyre.

In the subtropical gyre, the downward penetration of EKE from the thermocline is not significantly modified by the topographic smoothing performed in area A (upper panels of Fig. 4b, black and green curves). On the other hand, this important feature of the EKE field was shown to get very close to that of SIGMA when the LEVEL topography was globally smoothed (section 4c). It is likely that MTR, unaffected by the local smoothing in the LS experiment, confines the EKE near the surface in the subtropical gyre. This hypothesis is verified in section 6 .

\section{d. Summary-Impact of topographic smoothing in areas $A$ and $B$}

The topographic smoothing of the northern Scotia Sea, which is routinely performed in sigma-coordinate models, explains the separation of the local EKE maxima associated with the two fronts of the ACC, but does not alter the model dynamics in other regions.

In contrast, smoothing the LEVEL "raw" topography in the Agulhas region affects the whole subtropical gyre. This treatment improves the LEVEL solution by completely modifying the Agulhas rings production mechanism: the Agulhas Current becomes more baroclinic and retroflects farther west, forming there an anticyclonic cell whose deformations strongly suggest the presence of baroclinic instability. This process forms cyclonic and anticyclonic eddies, which have a more realistic (greater) diameter and disperse meridionally, as suggested by satellite data. Interestingly, these features become similar to those observed in the SIGMA experiment. Therefore, the use of a raw topography in the Agulhas region in LEVEL adversely affects the dynamics of the Agulhas Current and the Agulhas rings. More generally, the topographic smoothing applied routinely in sigma-coordinate models, and especially that performed in the Agulhas region, seems to have major local and remote (beneficial) effects on the EKE field in the subtropical gyre.

\section{Impact of mesoscale topographic roughness (MTR)}

The role of MTR is now investigated with the GS and GSR simulations. In the GSR LEVEL experiment, the topography in areas A and B is the same as in LS and GS. The Agulhas rings produced in GSR are thus expected to be very similar to those produced in LS and GS; this is confirmed by computer animations as shown in Figs. 5c and 5e. At distance from area A, the distribution of EKE in GSR is modified by introducing random MTR to the GS topography. Figure 3e and the black triangles of Figs. $4 \mathrm{a}$ and $4 \mathrm{~b}$ respectively show the surface EKE distribution, the subdomain-averaged vertical profile, and the downward penetration of EKE in the GSR experiment. 


\section{a. In the subtropical gyre}

Compared to that observed in GS, the EKE in GSR decreases below $1000 \mathrm{~m}$ and increases above $1000 \mathrm{~m}$ in the subtropical gyre (upper panels of Fig. 4a, red curves, black triangles). MTR thus moderates the downward penetration of EKE from the thermocline (upper panels of Fig. 4b, same colors). These midlatitude effects have been explained in idealized, process-oriented numerical studies (Böning 1989; Barnier and Le Provost 1989, 1993). According to these authors, MTR concentrates the deep flow at the scales of topographic mesoscale structures where it tends to be dissipated by lateral friction. The inverse energy cascade, which feeds the barotropic component of the EKE efficiently over a smooth seafloor, was shown to be inhibited by MTR. This enhances the EKE baroclinicity.

As shown by Beismann et al. (1999) with a quasigeostrophic model, relatively baroclinic Agulhas rings are less blocked by the Walvis Ridge than more barotropic ones. Indeed, the Agulhas rings found in the rough-bottomed experiments (GSR and pivot experiments) are more baroclinic, and are able to drift a greater distance across the subtropical gyre than in the smoothbottomed (SIGMA, GS, and LS) experiments. This is illustrated in computer animations (see Figs. 5c, 5e) by the increased penetration of the EKE maximum westward from the southern tip of Africa (cf. Figs. 3c and $3 \mathrm{e})$.

These two important effects of MTR (EKE baroclinization, partial decorrelation of surface-intensified eddy flows from topography), observed and studied in earlier idealized models, thus still persist in more realistic configurations.

\section{b. Within the ACC}

Unlike in the subtropical gyre, the introduction of MTR induces a decrease of EKE at all depths within the ACC (lower panels of Fig. 4a, red curve and black triangles). This subtropical/subpolar contrast was not investigated in earlier process-oriented studies that were focused on midlatitudes, but may be qualitatively explained by the Prandtl vertical scale:

$$
H_{p}=\frac{f_{0} L_{t}}{N}
$$

$H_{p}$ quantifies the depth over which topographic effects are expected to affect the water column upward from the ocean floor. Respectively, $f_{0}, L_{t}$, and $N$, denote the Coriolis parameter, the horizontal wavelength of topography, and the Brünt-Väisälä frequency. A simple scaling indicates that $f_{0}, N$, and the $L_{t}$ scales of the random MTR are respectively 1.5 times greater, 1.7 times smaller, and 1.3 times smaller at $50^{\circ} \mathrm{S}$ than at $30^{\circ} \mathrm{S}$ (the average latitudes of the southern and northern averaging subdomains defined in Fig. 1a). Topographic effects are thus expected to affect a depth two times greater in subpolar regions than in the subtropical gyre. This explains why MTR, either realistically (pivot, LS) or randomly (GSR) distributed, generally decreases the EKE up to the surface in the southern subdomains.

\section{c. Summary-Impact of MTR}

The differences found between GSR and GS are qualitatively the same as those found between LS and GS because both GSR and LS mainly differ from GS with respect to MTR. In fact, the EKE surface intensification induced by the artificial roughness (in GSR) is more intense than that induced by the "real" roughness (in LS), probably because the former is more pronounced than the latter (Fig. 1f), and is distributed more uniformly in the deep ocean.

Our five experiments can be easily classified into two categories according to the smooth or rough character of their topography, regardless of the model used and the shape of the topography in area A. First, Figs. 4b and 6 show that in most subdomains, the proportion of thermocline EKE reaching $3000 \mathrm{~m}$ seems more realistic (greater than 20\%) over the smooth bathymetries used in SIGMA and GS, but less than $12 \%$ over rough ones (pivot, LS, GSR). Second, the Agulhas rings found in the five configurations are clearly more able to persist over long distances across the subtropical gyre above rough topographies than above smooth ones. These two major properties of the eddy flow are therefore considerably affected by MTR.

It is worth noting that in the absence of MTR, both models (GS and SIGMA experiments) produce eddy flows that are similar with respect to the downward penetration of the EKE everywhere in the basin, and to the drift of the Agulhas rings in the subtropical gyre. This shows that the removal of MTR, performed routinely when preparing $13^{\circ}$ sigma-coordinate model bathymetries, modifies several aspects of the eddy-topography interactions in SIGMA, and contributes to differentiate them from those found in the LEVEL pivot experiment.

\section{Conclusions}

The present study was inspired by the numerous and significant differences found in the eddy field produced by a sigma-coordinate model and a geopotential-coordinate model implemented on similar South Atlantic $13^{\circ}$ configurations. These two types of model differ not only intrinsically in terms of their numerical formulations, but also with regard to their topographies. Indeed, a smoothing is performed on sigma-coordinate model topographies to reduce truncation errors in the computation of pressure gradient terms, whereas geopotentialcoordinate model topographies are usually built by a simple interpolation of the topographic dataset onto the model grid, without any particular smoothing. Our goal was to test whether some of the differences observed 
in the model solutions, usually attributed to different numerics, may be due to the treatment performed on the model bathymetries. The smooth-bottomed sigmacoordinate model (SIGMA) configuration was taken as a reference, and four simulations were performed with the geopotential-coordinate model (LEVEL) with different bathymetries.

Local smoothing of the LEVEL topography in the Agulhas region results in the eddy flow converging toward that of SIGMA throughout the subtropical gyre: the production mechanism, characteristics, and trajectories of the Agulhas rings, and the global EKE level between $40^{\circ}$ and $20^{\circ} \mathrm{S}$ at all depths, become similar to those observed in SIGMA. This demonstrates that the topographic smoothing performed in SIGMA in that particular area is a cause of several major differences in the eddy dynamics simulated by the two models in the subtropical gyre.

Previous process-oriented studies also suggest that mesoscale topographic roughness (MTR), which is usually retained in $13^{\circ}$ geopotential-coordinate models, but routinely (and necessarily) smoothed out in sigma-coordinate models, tends to reduce the downward penetration of EKE, and may limit the sensitivity of the Agulhas rings to the Walvis Ridge. It is interesting to note that these two dynamical features are distinguishing aspects of the smoothed-bottomed SIGMA solution with regard to the rough-bottomed LEVEL solution: in SIGMA, the EKE penetrates further downward (which seems more realistic) and the Agulhas rings are more blocked by the Walvis Ridge. We have shown that the presence of MTR in LEVEL (or, alternatively, its absence in SIGMA) largely explains those differences.

Some major circulation features, mostly located in the western basin, were not affected by topographic modifications in LEVEL. In particular, the separation of the Brazil Current from the coast, the northward overshoot of the Malvinas Current just west of it, and the mean and eddy flows around the Zapiola Drift were more realistic in SIGMA than in all LEVEL solutions. Even at a resolution of $16^{\circ}$, the same geopotential-coordinate model does not represent those regional features as well as SIGMA does (B. Barnier 2001, personnal communication). This strongly suggests that present LEVEL-type models (without an explicit parameterization of current-topography interactions) require a significantly higher horizontal resolution than sigmacoordinate models to represent correctly topographic effects at a given wavelength. Our experiments highlight another intrinsic difference between the models: with a topography appearing much smoother than in SIGMA, LEVEL simulates the same downward penetration of EKE. This shows that the piecewise constant topography used in the geopotential-coordinate model intrinsically induces more topographic roughness than the piecewise linear topography used in sigma-coordinate model. It turns out that those intrinsic differences between the two models could be identified without building a LEV-
EL configuration with the SIGMA topography and comparing its solution with that in SIGMA (such an experiment had been evoked in section 2). This identification could be done instead by interpreting the striking similarities found between the eddy flow in GS and in SIGMA, produced by different models over different topographies. A LEVEL simulation with SIGMA topography may be useful to confirm our conclusions, but was not necessary in the present study.

It will be important to understand and quantify how geopotential- and sigma-coordinate systems affect the form drag and bottom friction effects, and, in turn, the vertical distribution of EKE. This is particularly necessary for geopotential-coordinate models since they are implemented with high-wavenumber topographies. Dedicated studies are also needed to gain insights into the dynamical balances that control the path and unstable character of the Agulhas Current in the two coordinate systems, and finally to explain why this current produces rings that are more realistic in LEVEL with local smoothing and in SIGMA. Finally, the present results were obtained in the "eddy-permitting" regime on a particular basin: additional simulations on various domains at various resolutions would be helpful to generalize our findings. These investigations lie beyond the scope of this paper; they will require some analytical work and highly idealized numerical experiments. Because the impact of MTR on the vertical distribution of EKE and on the eddy-ridge interactions was proven robust with different types of models at various resolutions in previous studies, one may anticipate, though, that the qualitative impact of topographic smoothing on these features in geopotential coordinate models would remain similar in other domains and at higher resolution.

To conclude, it seems that present geopotential-coordinate models are not able to take full advantage of their a priori more realistic (rougher and steeper) topographies. In the absence of an adequate parameterization of current-topography interactions, aiming at the most detailed and steep topography for a given grid resolution is not necessarily the best way to define a high-resolution model configuration. Further research needs to be conducted to better understand the impact of topography on currents in the real ocean, and to represent it in numerical models.

Acknowledgments. The authors were supported by the Centre National d'Etudes Spatiales (Postdoctoral Fellowship), the Climate Institute, a Center of Excellence sponsored by the Florida State University Research Foundation, and the Centre National de la Recherche Scientifique. Support for computations was provided by the Institut du Développement et des Resources en Informatique Scientifique. We would like to thank J. J. O'Brien and W. K. Dewar for their support and discussions during the preparation of the manuscript, $\mathrm{K}$. Béranger for providing us with the output data of the sigma-coordinate model, S. Grall and K. Guizien for 
processing the WOCE current meter data, and two anonymous reviewers whose work contributed to improve the paper.

\section{REFERENCES}

Adcroft, A., and D. Marshall, 1998: How slippery are piecewiseconstant coastlines in numerical ocean models? Tellus, 50, 98108.

Barnier, B., and C. Le Provost, 1989: General circulation of the midlatitude ocean: Coupled effects of variable wind forcings and bottom topography roughness on the mean and eddy circulation. Mesoscale/Synoptic Coherent Structures in Geophysical Turbulences, J. C. J. Nihoul and B. M. Jamart, Eds., Elsevier, 387405.

, and — 1993: Influence of bottom roughness on the jet and inertial recirculation of a mid-latitude gyre. Dyn. Atmos. Oceans, 18, 29-65.

P. Marchesiello, A. P. de Miranda, J.-M. Molines, and M. Coulibaly, 1998: A sigma-coordinate primitive equation model for studying the circulation in the South Atlantic. Part I: Model configuration with error estimates. Deep-Sea Res., Part I, 45, 573-608.

-, T. Reynaud, A. Beckmann, C. W. Bo " ning, J.-M. Molines, Barnard, and Y. Jia, 2001: On the seasonal variability and eddies in the North Brazil Current: Insights from model intercomparison experiments. Progress in Oceanography, Vol. 48, Pergamon, 195-230.

Beckmann, A., and D. Haidvogel, 1993: Numerical simulation of flow around a tall, isolated seamount. Part I: Problem formulation and model accuracy. J. Phys. Oceanogr., 23, 1736-1753.

Beismann, J.-O., R. H. Käse, and J. R. E. Lutjeharms, 1999: On the influence of submarine ridges on translation and stability of Agulhas rings. J. Geophys. Res., 104, 7897-7906.
Béranger, K., 2000: Application d'une nouvelle formulation des conditions atmosphériques de surface pour la simulation de la circulation et des masses d'eau dans l'océan Atlantique Sud. Ph.D. thesis, Université J. Fourier, Grenoble, France, 303 pp.

Boebel, O., C. Barron, P. Richardson, J. Lutjeharms, and R. Davis, 2000: Mixing of Antarctic Intermediate Water from the Atlantic and Indian Ocean at the Agulhas Retroflection. WOCE Int. Newsl., 39, 9-12.

Böning, C. W., 1989: Influences of a rough bottom topography on flow kinematics in an eddy-resolving model. J. Phys. Oceanogr., 19, 77-97.

de Miranda, A. P., B. Barnier, and W. K. Dewar, 1999: On the dynamics of the Zapiola anticyclone. J. Geophys. Res., 104, 21 $137-21149$.

Ducet, N., P.-Y. Le Traon, and G. Reverdin, 2000: Global high-resolution mapping of ocean circulation from TOPEX/Poseidon and ERS-1 and -2. J. Geophys. Res., 105, 19 477-19 498.

New, A. L., S. Barnard, P. Herrmann, and J.-M. Molines, 2001: On the origin and pathway of the saline inflow to the Nordic seas. Progress in Oceanography, Vol. 48, Pergamon, 255-287.

Penduff, T., B. Barnier, K. Béranger, and J. Verron, 2001: Comparison of near-surface mean and eddy flows from two numerical models of the South Atlantic Ocean. J. Geophys. Res., 106, 16 85716867.

Peterson, R. G., and L. Stramma, 1991: Upper-level circulation in the South Atlantic Ocean. Progress in Oceanography, Vol. 26, Pergamon, 1-73.

Smith, W. H. F., and D. T. Sandwell, 1997: Global seafloor topography from satellite altimetry and ship depth soundings. Science, 227, 1956-1962.

Tréguier, A.-M., and Coauthors, 1999: The CLIPPER project: High resolution modeling of the Atlantic. Int. WOCE Newsl., 36, 3-5.

Willebrand, J., and Coauthors, 2001: Circulation characteristics in three eddy-permitting models of the North Atlantic. Progress in Oceanography, Vol. 48, Pergamon, 123-161. 